\title{
A Clinico-Anatomical Study of Strabismus in a Tertiary Care Hospital
}

\author{
Dr Sarita Behera ${ }^{1}$, Dr Bijaya Kumar Dutta ${ }^{2}$ Dr Ravindra Kumar Chowdhury ${ }^{3}$ \\ Dr Mamata $\mathrm{Sar}^{4}$ \\ Department of Anatomy ${ }^{1,2,4}$ \& Department of Ophthalmology ${ }^{3}$ \\ V.S.S.Medcal College, Burla, Sambalpur, Odisha, India
}

\begin{abstract}
This prospective study was conducted about the clinical profile, extraocular muscle involvement, epidemiology and the etiology of 162 cases of manifest strabismus attending the Ophthalmology outpatient department from July 2009 to July-2011. Incidence of manifest strabismus was found to be 0.63\%, of which $63 \%$ were paralytic and $37 \%$ non paralytic, $66 \%$ were esotropia and $34 \%$ exotropia. Paralytic esotropia was common in the age group of 41-50 years (46.4\%) and nonparalytic in 0-10 years (47.4\%). Males dominated over females whether esotropia or exotropia. Paralytic exotropia was common in 41-50 years (45.6\%) and non paralytic in 0-10 years (45.5\%). Paralytic strabismus was common in the lower socioeconomic group (52.9\%) and non paralytic in middle and higher class (86.7\%). Abduction defect was found in $73.5 \%$ due to lateral rectus muscle involvement. Abducent nerve palsy was the most common cause of paralytic strabismus (56.8\%) followed by oculomotor nerve (21.6\%). No isolated $4^{\text {th }}$ nerve involvement was encountered. Involvement of more than one cranial nerves was found in 21.6\%.Most of the patients presented with deviation of eye followed by diplopia and defective vision. Vascular involvement was the commonest etiology in the paralytic group. Ophthalmologists need to be trained and well equipped strabismus clinics should be established in this part of the country.
\end{abstract}

Key words: Strabismus,Esotropia,Exotropia,Extraocular muscles

\section{Introduction}

Strabismus (Crooked eye or squint) is a condition in which the eyes are not properly aligned with each other. It typically involves a lack of coordination between the extra ocular muscles. It can either be a disorder of brain coordinating the eyes or one or more muscles. Two to four percent of world's total child population are reported to have strabismus. Clinically strabismus can be classified as true (Heterotropia) or latent (Heterophoria) type. In true or manifest type, the manifestations are always present. In latent type, the manifestations appear during stressful periods only. Again the manifest strabismus can be of paralytic or non paralytic type, the former mainly involving the extraocular muscles. A set of seven extra ocular muscles $(4$ rectii, 2 obliques and levator palpebrae superioris) control the movements of each eye. Rectus muscles are superior, inferior, medial and lateral rectus. The oblique muscles include superior and inferior oblique..As.one of the least developed wings of ophthalmology is strabismus and most of the earlier studies deal with its clinical aspect and management,in this study we focused on clinical profile,extraocular muscle involvement, epidemiology and etiology of 162 cases of strabismus.to highlight its anatomical aspect correlated with clinical findings.

\section{Materials\& Methods}

This prospective study was carried out from June 2009 to June 2011. All manifest strabismus cases of different types independent of age \& sex attending the outpatient department of Ophthalmology were included in the study.

A careful history regarding age of onset, duration, eye affected, whether intermittent or constant, alternating or fixed, precipitating factors, diurnal variation of deviation was obtained.

Any past history of prescription of glasses or occlusion, family history of strabismus in blood relatives, defective vision and refractive error was recorded. General and systemic examinations along with examination of eye and ocular adenexa were done.

The specific tests like Cover-uncover test,Prism bar cover test,Hirschberg test,Worth four dot test,Synatophore test,Baggoloni striated glass test and Forced duction test were done whenever required.

\section{Observation:}

Out of 25615 patients attending the outpatient department of ophthalmology, 162 patients diagnosed as manifest strabismus were studied and the following observations were made: 
Table-1

Incidence of Manifest Strabismus

\begin{tabular}{|l|l|l|}
\hline Total no. of patients & $\begin{array}{l}\text { Total number of } \\
\text { Manifest Strabismus }\end{array}$ & Incidence (\%) \\
\hline 25615 & 162 & 0.63 \\
\hline
\end{tabular}

TABLE-2

Type of Manifest Strabismus (According to Etiology)

\begin{tabular}{|c|c|c|}
\hline Type of strabismus & No.of Patients & Percentage \\
\hline Paralytic & 102 & 63.0 \\
\hline Nonparalytic & 60 & 37.0 \\
\hline
\end{tabular}

TABLE-3

Type of Manifest Strabismus (According to Deviation)

\begin{tabular}{|c|c|c|}
\hline Type of Strabismus & No.of Patients & Percentage \\
\hline Esotropia & 107 & 66.0 \\
\hline Exotropia & 55 & 34.0 \\
\hline
\end{tabular}

TABLE-4

Epidemiological Profile \& Etiology

\begin{tabular}{|l|l|l|l|l|}
\hline \multirow{2}{*}{ Criteria } & Paralytic & \multicolumn{2}{l|}{ Nonparalytic } \\
\cline { 2 - 5 } & Esotropia & Exotropia & Esotropia & Exotropia \\
\hline Commonest age group & $41-50(46.4 \%)$ & $41-50(45.6 \%)$ & $0-10(47.4 \%)$ & $0-10(45 \%)$ \\
\hline Sex & Male>Female & Male>Female \\
\hline Socioeconomic status(SES) & Common in lower SES & $\begin{array}{l}\text { Common in middle \& } \\
\text { higher SES }\end{array}$ \\
\hline
\end{tabular}

Table-5

Type of Extraocular Muscle Function Defect

\begin{tabular}{|c|c|c|}
\hline EOM function defect & No of patients $(\mathrm{n}=102)$ & Percentage \\
\hline Abduction & 75 & 73.5 \\
\hline Adduction & 25 & 24.5 \\
\hline Elevation & 27 & 26.5 \\
\hline Depression & 23 & 22.5 \\
\hline
\end{tabular}

Table 6

Extraocular Muscle Involvement

\begin{tabular}{|l|c|c|}
\hline \multicolumn{1}{|c|}{ EOM } & No of patients $(\mathrm{n}=102)$ & Percentage \\
\hline Lateral rectus & 75 & 73.5 \\
\hline Medial rectus & 25 & 24.5 \\
\hline Superior rectus & 27 & 26.4 \\
\hline Inferior rectus & 23 & 22.5 \\
\hline Inferior oblique & 22 & 21.5 \\
\hline Superior oblique & 5 & 4.9 \\
\hline LPS & 18 & 17.6 \\
\hline
\end{tabular}

Table 7

Nerve involvement

\begin{tabular}{|l|c|c|}
\hline \multicolumn{1}{|c|}{ Nerve } & No of patients $(\mathrm{n}=102)$ & Percentage \\
\hline Abducent & 58 & 56.8 \\
\hline Oculomotor & 22 & 21.6 \\
\hline Trochlear & 0 & 0 \\
\hline Mixed & 22 & 21.6 \\
\hline
\end{tabular}

Table 8

Clinical symptoms

\begin{tabular}{|l|c|c|}
\hline \multicolumn{1}{|c|}{ Symptom } & No of patients $(\mathrm{n}=162)$ & Percentage \\
\hline Deviation & 142 & 87.6 \\
\hline Defective vision & 73 & 45.0 \\
\hline Diplopia & 91 & 56.1 \\
\hline Headache & 87 & 53.7 \\
\hline Head tilt & 69 & 42.5 \\
\hline
\end{tabular}


Table 9

Etiology of paralytic strabismus

\begin{tabular}{|l|c|c|}
\hline \multicolumn{1}{|c|}{ Causes } & No of patients (n=102) & Percentage \\
\hline Vascular & 44 & 43.1 \\
\hline Inflammatory & 14 & 13.8 \\
\hline Head trauma & 4 & 3.9 \\
\hline Tumor (SOL) & 2 & 1.9 \\
\hline Congenital & 1 & 0.9 \\
\hline Pseudotumor of orbit & 10 & 9.8 \\
\hline Dysthyroid orbitopathy & 8 & 7.9 \\
\hline Orbital trauma & 4 & 3.9 \\
\hline Idiopathic & 15 & 14.8 \\
\hline
\end{tabular}

Table 10

Etiology of Nonparalytic strabismus

\begin{tabular}{|l|c|c|}
\hline \multicolumn{1}{|c|}{ Causes } & No of patients $(\mathrm{n}=60)$ & Percentage \\
\hline High refractive error & 35 & 58.4 \\
\hline Opacity in media & 14 & 23.3 \\
\hline Retinal diseases & 2 & 3.3 \\
\hline Abnormal AC/A ratio & 5 & 8.3 \\
\hline Congenital & 4 & 6.7 \\
\hline
\end{tabular}

\section{Discussion}

Most of the studies done on strabismus during 1955 to 2007 reveal the incidence to be more than $1 \%$ whereas our study reported the incidence to be $0.6 \%$. This may be due to lack awareness regarding treatment of strabismus .The ratio of esotropia:exotropia was found to be 1.94:1 which is consistent with Mohney et al(2007)[1],Robai et al (2005)[2] and Ohlsson et al (1999)[3],however the ratio was reverse as per Lim et al(2004)[4],Nepal et al(2003)[5] and Matsuo et al(2003)[6].More number of esotropia in our study is due to higher incidence of $6^{\text {th }}$ neve palsy. Paralytic esotropia was common in 41-50 years $(45.6 \%)$ and non paralytic in 0-10 years(45.5\%) which is consistent with Suraj Shakya et al(2004)[7].Paralytic exotropia was also common in 41-50 years $(45.6 \%)$ and non paralytic in 0-10 years (45.5\%).Further Males dominated over females in our study irrespective of the type of strabismus. This is probably because males are given priority to be brought to the hospital for strabismus. Paralytic type was more common in lower socioeconomic group (52.9\%) and non paralytic in middle and higher class $(86.7 \%)$. The lack of awareness among people regarding the treatment of strabismus and social taboo associated with the disease obstruct the lower socioeconomic group to attend the strabismus clinic. This may be the possible cause for the higher incidence of non paralytic squint in middle and higher economic class.However the annoying symptom of diplopia in paralytic type compels the lower socioeconomic group to attend the ophthalmologists.98\% of total paralytic strabismus was unilateral in our study which is consistent with AbdolrezaMedghalahi et al[8],J.Holme et al[9],SurajShakya et al[7] .Abduction defect was the most common extraocular function defect because of increased incidence $6^{\text {th }}$ nerve palsy in paralytic group.Multiple cranial nerve involvement was seen in $21.6 \%$ of paralytic group which is quite higher as compared to study by AbdolrezaMedghalahi et al[8] because trauma was an important cause of paralytic strabismus in our study which involved multiple nerves. We did not come across isolated $4^{\text {th }}$ nerve palsy which is interesting to note.However AbdolrezaMedghalahi et al[8] found the isolated $6^{\text {th }}$ nerve palsy in $70.2 \%$ of cases and Jonathan Holmes et al[9] found $4^{\text {th }}$ nerve as thecommomest involvement. As most of the cases are paralytic in origin in our study,deviation of eye $(87.6 \%)$ and diplopia $(56.1 \%)$ were the predominant symptoms which is consistent with SurajShakya et al[10].The commonest etiology in paralytic group was of vascular origin which is consistent with Moster et $\mathrm{al}^{10}$ and Berlit et al[11].High refractive error and opacity in media were found to be the major causes of non paralytic strabismus .Further, the deviation in the non paralytic strabismus was mainly because of amblyopia.

\section{Conclusion}

The anatomical knowledge of extra ocular muscles, their function and knowledge about ocular nerves is highly essential for correct diagnosis and proper treatment of strabismus population. This study will help the ophthalmologists to know the incidence, various prevailing causes, laterality, socioeconomic status of the affected patients and about the age \& sex distribution of strabismus, so that they can plan for a well equipped strabismus clinic with trained persons to lessen the burden of this socially cursed disease for which many people are suffering since a long time in this part of the country. 


\section{References}

[1]. Mohney BG. Common forms of childhood strabismus in an incidence cohort.Am J Ophthalmol. 2007 Sep; $144(3): 465-7$.

[2]. Robaei D, Rose KA, Kifley A, Cosstick M, Ip JM, Mitchell P. Factorsassociated with childhoodstrabismus: findings from a population-based study.Ophthalmology. $2006 \mathrm{Jul} ; 113(7): 1146-53$.

[3]. Ohlsson J, Villarreal G, Sjöström A, Cavazos H, Abrahamsson M, Sjöstrand J. Visual acuity, amblyopia, and ocular pathology in 12- to 13-year-old children in Northern Mexico.J AAPOS. 2003 Feb;7(1):47-53.

[4]. Lim HT, Yu YS, Park SH, Ahn H, Kim S, Lee M, Jeong JY, Shin KH, Koo BSThe Seoul Metropolitan Preschool Vision Screening Programme: results from South Korea.Br J Ophthalmol. 2004 Jul;88(7):929-33.

[5]. Nepal BP, Koirala S, Adhikary S, Sharma AK. Ocular morbidity in schoolchildren in Kathmandu.Br J Ophthalmol. 2003 May;87(5):531-4.

[6]. Matsuo T, Matsuo C. The prevalence of strabismus and amblyopia in Japanese elementary school children.Ophthalmic Epidemiol. 2005 Feb;12(1):31-6.

[7]. ShakyaS,AgrawalJP,Ray P. 1Profile of isolated sixth cranial nervepalsy: A hospital based study J Neuroscience 1:32-35, 2004

[8]. AbdolrezaMedghalchi.Survey of Paralytic Strabismus: A Regional SurvayActaMedicaIranica2009;47(3) : $221-224$.

[9]. Holmes JM, Leske DA, Christiansen SP. Initial treatment outcomes in chronic sixth nerve palsy.J AAPOS. 2001 Dec;5(6):370-6.

[10]. Moster ML, Savino PJ, Sergott RC, Bosley TM, Schatz NJ. Isolatedsixth-nerve palsies in youngeradults.ArchOphthalmol. 1984 Sep;102(9):1328-30.

[11]. Berlit P, Reinhardt-Eckstein J, Krause KH. [Isolated abducens paralysis--a retrospective study of 165 patients].FortschrNeurolPsychiatr. $1989 \mathrm{Jan} ; 57(1): 32-40$. 